\title{
Overweight is not a comorbidity factor during childhood asthma: the GrowthOb
} study

\author{
Bruno Mahut*,\#, ${ }^{*}$, Nicole Beydon ${ }^{\tau,+}$ and Christophe Delclaux*, ${ }^{*}, \S_{,}$,
}

ABSTRACT: While being overweight is a risk factor for subsequent asthma in children, the importance of body mass index (BMI) as a comorbidity factor remains debated. The aim of this study was to assess the relationships between being overweight and the characteristics of childhood asthma.

The BMI, BMI z-scores and International Obesity Task Force (IOTF) grades were evaluated in asthmatic children according to atopic status, symptoms during the past 3 months, exercise breathlessness, treatment and lung function in 6-15-yr-old children with confirmed asthma.

491 asthmatic children (mean \pm SD age $10.8 \pm 2.6$ yrs; 179 females) were prospectively enrolled. There were $78(15.5 \%)$ overweight (IOTF grade 1) and eight (1.6\%) obese (grade 2) children. The children's BMI z-scores did not differ according to atopy, exacerbation, symptom-free days or treatment. The BMI z-score correlated positively with forced vital capacity and forced expiratory volume in $1 \mathrm{~s}$ in females, which could be related to earlier puberty in overweight females (growth spurt with increased volumes). Compared with normal weight children, overweight and obese children had reduced lung volume ratios (functional residual capacity/total lung capacity (TLC) and residual volume/TLC), no evidence of airflow limitation and similar symptoms.

In conclusion, the observed functional relationships with BMI are not specific to asthma and being overweight is not associated with significant clinical impacts on asthma during childhood.

\section{KEYWORDS: Body mass index, lung function, lung volumes, obesity, z-score}

$\mathrm{n}$ the paediatric population, an increase in body mass index (BMI) is associated with the increased incidence [1] and prevalence [2] of asthma. The role of being overweight as a comorbidity factor is said to be "possibly important, yet poorly studied" [3]. Conflicting results on the relationship between BMI and asthma phenotype have been published. Being overweight has been associated with the severity of asthma exacerbations [4, 5], as well as with poor asthma control [6]. However, in an important retrospective study, no effect of BMI on the time required to achieve control of asthma or on the ability to maintain good control of asthma was shown [7]. BMI per se has also been inconsistently correlated with clinical symptoms, such as coughing and wheezing on exertion [8], and with an increase in the number of symptom days and in the number of exacerbations in females only [9]. Such discrepancies between results might partially be due to the various cut-off points of BMI that are used across studies to define overweight and obesity (frequently the 85th or 95th percentiles). Normal values of BMI are age- and sex-specific throughout childhood; therefore, the transformation of children's BMI values into sex- and age-specific $\mathrm{z}^{-}$ scores is mandatory in order to ascertain the relationships between stoutness and clinical events and lung function. To further study the effect of overweight/obesity during childhood, the grades of COLE and co-workers [10,11] of the International Obesity Task Force (IOTF) are regarded as the gold standard for BMI. While looking for a relationship between BMI and lung function in asthmatic children, the Childhood Asthma Management Program (CAMP) reported a decrease in the forced expiratory volume in $1 \mathrm{~s}$ (FEV1)/forced vital capacity (FVC) ratio with increasing BMI, suggesting a link between being overweight and asthma severity [8]. This latter study enrolled 1,039 children (aged 5-12 yrs) with mild-to-moderate asthma; age-, ethnicity- and sex-specific BMI percentile cut-off points of $85 \%$ for overweight $(17.4 \%)$ and $95 \%$ for obese $(11.8 \%)$ were used [8]. These authors found that increasing BMI was (mainly) associated with increasing FEV1 and FVC, resulting in decrements in the FEV1/FVC ratio with increasing BMI [8].

\section{AFFILIATIONS}

*AP-HP, Hôpital Européen GeorgesPompidou, Service de Physiologie, Clinique de la Dyspnée

'Mosquito Respiratory Research Group,

${ }^{+}$AP-HP, Hôpital Armand-Trousseau, Unité Fonctionnelle d'Explorations Fonctionnelles Respiratoires,

§Université Paris Descartes, Sorbonne Paris Cité, Faculté de Médecine,

${ }^{f}$ CIC Plurithématique 9201, AP-HP/ INSERM, Hôpital Européen GeorgesPompidou, Paris, and

\#Cabinet La Berma, Antony, France.

CORRESPONDENCE

C. Delclaux

Service de Physiologie

Clinique de la Dyspnée

Hôpital Européen Georges Pompidou

20 rue Leblanc

75015 Paris

France

E-mail: christophe.delclaux@

egp.aphp.fr

Received:

June 162011

Accepted after revision:

Aug 172011

First published online:

Sept 012011 
Interestingly, the increase in BMI in healthy childhood could also be associated with an increase in forced expiratory volumes [8, 12], but, unfortunately, no measures of static lung volumes were obtained in these studies, hampering clarification of the lung function patterns in obese asthmatic children. Finally, a sex effect on the relationship between BMI and lung function was noted.

We hypothesised that using two different approaches to express BMI (quantitatively, using z-scores, and qualitatively, using IOTF) should provide new insights into the relationships between being overweight and asthma symptoms and lung function. Therefore, we conducted a paediatric observational cross-sectional study with prospectively defined recruitment that had three main characteristics: 1) overweight/obesity was not only evaluated using raw BMI values, but also using BMI z-scores and IOTF grading; 2) spirometry was evaluated using the recent reference values developed by the Asthma UK Collaborative Initiative, which incorporated age and height [13]; and 3) body plethysmography lung volumes were systematically measured.

\section{PATIENTS AND METHODS}

We prospectively enrolled asthmatic patients referred to La Berma clinic (Antony, France) between January 1, 2010 and April 15 , 2011. Inclusion criteria were: age between 6 and $15 \mathrm{yrs}$, diagnosis of confirmed asthma defined according to the clinical symptoms of asthma (Global Initiative for Asthma (GINA) guidelines [14]), associated with a documented bronchodilator response (FEV1 increase $>12 \%$ from baseline or specific airway resistance ( $\mathrm{s} R \mathrm{aw}$ ) decrease $\geqslant 42 \%$ from baseline) in the history [15], and no severe exacerbation or oral steroid treatment in the previous 7 days.

BMI was calculated (weight/height squared) and adjusted for age and sex to give a standard BMI deviation score using British 1990 Growth Reference Data. We used international cut-off points (IOTF grades) based on adult BMI cut-off points to classify children aged 2-18 yrs as being underweight (grades -1 and -2), normal weight (grade 0 ), overweight (grade 1 ) or obese (grade 2), according to age, sex and BMI score $[10,11]$.

In accordance with recent recommendations, severe exacerbation was defined as an exacerbation requiring $>3$ days of systemic corticosteroid treatment or requiring a visit to the emergency department [16]. The number of symptom-free days (no coughing, wheezing or chest tightness) during the last 3 months was recorded and reported as a percentage $(100 \times$ free days $/ 90)$. Exercise breathlessness was characterised as: no complaints; complaints when playing team sports; and complaints during long-distance racing only.

Our Ethics Committee (the Institutional Review Board of the French language society for respiratory medicine - Société de Pneumologie de Langue Française) waived the need for signed consent due to the observational nature of the study (GrowthOb study), according to French Law, but all children and parents were informed of the recording of clinical and physiological data. The database used in the study has been declared to the French regulatory agency for computer data collection (Commission Nationale Informatique et Libertés, number 1408710).

\section{Pulmonary function tests}

Bronchodilator treatment was withheld for $12 \mathrm{~h}$ before the lung function test. Exhaled nitric oxide fraction was first measured using the NIOX Nitric Oxide Analyzer (Aerocrine AB, Solna, Sweden), as previously described [17]. Lung function was evaluated at baseline and after bronchodilator administration (400 $\mu \mathrm{g}$ of salbutamol with a space inhaler) using a body plethysmograph (MasterScreen Body; Jaeger, CareFusion, San Diego, CA, USA) that was calibrated daily, as recommended. All measurements were performed while the child was seated and breathing through a mouthpiece and a bacterial filter, whilst wearing a nose clip. Plethysmographic measurements were performed on the children (at least sRaw and forced residual capacity (FRC) in the younger children) as previously described $[15,18]$. Specific airway resistance was measured during panting and sRaw were recorded [19]. The best spirometry out of three reproducible manoeuvres was recorded. The reference values used for spirometry and static lung volumes were those of STANOJEVIC et al. [13] and those recommended by STOCKS and QUANJER [20], respectively.

\section{Statistical analysis}

Design of the analyses was as follows. We first analysed the relationships between $\mathrm{BMI}$ and both clinical and functional characteristics in order to enable comparisons with previous studies. Then, we analysed the same relationships using BMI and functional z-scores for both the whole population and according to sex. Corrections for multiple comparisons were performed to examine the impact of the number of tests on the p-value (correction according to BENJAMINI and YeKUTIELI [21]).

We calculated our sample size based on a prevalence of children in France who were overweight by $15 \%$ to allow multivariate analyses that included a maximum of five variables $(5 \times 15$ patients $=15 \%$ of the population, i.e. 500 children) [22]. Analyses were performed using indices expressed as the $\mathrm{z}$-score because expressing observed data as \% predicted is incorrect, as the scatter in predicted values is not proportional to the predicted value over a large range of heights and ages [23]. The z-score is a unitless number calculated according to the child's height, age and sex. The variables are expressed as mean $\pm \mathrm{SD}$ (z-score) or median (interquartile range) where appropriate. Correlations were assessed using Pearson's or Spearman's correlations. Intergroup comparisons were made using parametric (ANOVA and paired t-tests) or nonparametric (Mann-Whitney and Kruskal-Wallis tests) tests where appropriate. Statistical analyses were performed using StatView ${ }_{\circledR}$ software (SAS Institute Inc., Cary, NC, USA).

\section{RESULTS}

The clinical and functional characteristics of the 491 children who were enrolled in this study are presented in tables 1 and 2. All children fulfilling the inclusion criteria were enrolled. A severe exacerbation during the past 3 months was reported in 13\% of the children, which corresponded to an annual rate of 0.52 severe exacerbations per child per year.

The BMI z-score was normally distributed (KolmogorovSmirnov test). There were 76 overweight children (IOTF grade $1 ; 15.5 \%, 95 \%$ CI $12.3-18.7 \%$ ) and eight obese children (IOTF grade $2 ; 1.6 \%, 95 \%$ CI $0.5-2.8 \%$ ). Due to the small number of very thin (grade -2) and obese children, the IOTF classification was rearranged into three groups: underweight, normal and overweight. The age and sex of the children did not differ 
TABLE 1 Clinical characteristics of the population

\begin{tabular}{|c|c|}
\hline Total subjects $\mathrm{n}$ & 491 \\
\hline \multicolumn{2}{|l|}{ Anthropometrics } \\
\hline Females/males n & $179 / 312$ \\
\hline Age yrs & $10.8 \pm 2.5$ \\
\hline Height $\mathrm{cm}$ & $144 \pm 16$ \\
\hline Height z-score & $0.19 \pm 1.0$ \\
\hline Weight kg & $39 \pm 14$ \\
\hline Weight z-score & $0.29 \pm 0.98$ \\
\hline BMI & $18.2 \pm 3.1$ \\
\hline BMI z-score & $0.25 \pm 1.02$ \\
\hline \multicolumn{2}{|l|}{ IOTF classification } \\
\hline Grade -2 & $2(0)$ \\
\hline Grade -1 & $28(6)$ \\
\hline Grade 0 & $377(77)$ \\
\hline Grade 1 & $76(15)$ \\
\hline Grade 2 & $8(2)$ \\
\hline \multicolumn{2}{|l|}{ History } \\
\hline Birthweight kg ${ }^{\#}$ & $3.290 \pm 0.515$ \\
\hline Atopic dermatitis & $217(44)$ \\
\hline Early wheezing & $210(43)$ \\
\hline Age at first symptoms (if no early wheezing) yrs & $4(2.5-6.0)$ \\
\hline Duration of follow-up months & $40(19-71)$ \\
\hline Emergency department visit ${ }^{+}$ & $158(44)$ \\
\hline Parental smoking ${ }^{\S}$ & $98(20)$ \\
\hline \multicolumn{2}{|l|}{ Atopic status $f$} \\
\hline Negative & $79(17)$ \\
\hline One positive & $109(24)$ \\
\hline More than one positive & $267(59)$ \\
\hline \multicolumn{2}{|l|}{ Treatment } \\
\hline$\beta$-agonist on demand & $168(34)$ \\
\hline ICS dose $\mathrm{A}^{\# \#} \mu \mathrm{g} \cdot$ day ( $\mathrm{n}$ treated; \%) & $306 \pm 204(323 ; 66)$ \\
\hline LABA & $290(59)$ \\
\hline \multicolumn{2}{|l|}{ Resting symptoms in the past 3 months } \\
\hline No symptom & $220(45)$ \\
\hline Symptom-free days \% & $94 \pm 10$ \\
\hline Severe exacerbation & $64(13)$ \\
\hline \multicolumn{2}{|l|}{ Exercise complaints } \\
\hline No complaint & $295(60)$ \\
\hline Long-distance race & $146(30)$ \\
\hline Team play & $50(10)$ \\
\hline
\end{tabular}

Data are presented as mean $\pm \mathrm{SD}, \mathrm{n}(\%)$ or median (interquartile range), unless otherwise stated. BMI: body mass index; IOTF: International Obesity Task Force; ICS: inhaled corticosteroids; LABA: long-acting $\beta$-agonist. ${ }^{\#}: n=355$; ๑ $\mathrm{n}=489 ;^{+}: \mathrm{n}=359 ;^{\S}: \mathrm{n}=491 ;{ }^{f}: 455$ (93\%) tested; \#\#: the dose is given as beclomethasone-equivalent daily dose.

between the three grades of IOTF populations $(p=0.35$ and $\mathrm{p}=0.46$, respectively).

\section{Relationships between clinical and functional data and BMI or BMI z-score}

The relationship between BMI and BMI z-score, and clinical and functional characteristics are presented in table 3.

The BMI was influenced by both age and sex, while a statistically significant positive relationship was only shown between the BMI z-score and age. Considering the population as a whole, we
TABLE 2 Functional characteristics of the population

\begin{tabular}{|c|c|c|}
\hline & $\begin{array}{c}\text { Before } \\
\text { bronchodilation }\end{array}$ & $\begin{array}{c}\text { After } \\
\text { bronchodilation }\end{array}$ \\
\hline $\begin{array}{l}\text { Best sRaw reversibility } \\
\text { in the past \% baseline }\end{array}$ & \multicolumn{2}{|c|}{$-52 \pm 8$} \\
\hline $\begin{array}{l}\text { Best FEV1 reversibility } \\
\text { in the past } \% \text { baseline }\end{array}$ & \multicolumn{2}{|c|}{$23 \pm 11$} \\
\hline FeNO ppb & \multicolumn{2}{|l|}{$27(15-43)(259)$} \\
\hline \multicolumn{3}{|l|}{ Spirometry } \\
\hline FVC \% pred & $106 \pm 12(445)$ & $107 \pm 12(410)$ \\
\hline FEV1 $\%$ pred & $96 \pm 12(445)$ & $104 \pm 11(410)$ \\
\hline $\mathrm{FEV}_{1} / \mathrm{FVC} \%$ & $79 \pm 7(445)$ & $84 \pm 6(410)$ \\
\hline FEV1/FVC \% pred & $90 \pm 8(445)$ & $96 \pm 7(410)$ \\
\hline FEF25-75\% \% pred & $76 \pm 20(445)$ & $94 \pm 20(410)$ \\
\hline \multicolumn{3}{|l|}{ Plethysmography } \\
\hline sRaw $\mathrm{kPa} \cdot \mathrm{s}^{-1}$ & $1.03 \pm 0.26(491)$ & $0.70 \pm 0.16(450)$ \\
\hline TLC \% pred & $102 \pm 11(445)$ & $100 \pm 10(410)$ \\
\hline FRC $\%$ pred & $103 \pm 18(491)$ & $98 \pm 10(450)$ \\
\hline $\mathrm{RV} \%$ pred & $93 \pm 24(445)$ & $83 \pm 21(410)$ \\
\hline $\mathrm{FRC} / \mathrm{TLC}$ & $0.49 \pm 0.06(445)$ & $0.48 \pm 0.06(410)$ \\
\hline $\mathrm{RV} / T L \mathrm{C}$ & $0.22 \pm 0.05(445)$ & $0.20 \pm 0.04(410)$ \\
\hline
\end{tabular}

Data are presented as median (interquartile range) ( $n$ available) or mean $\pm S D$ ( $n$ available). sRaw: specific airway resistance; FEV1: forced expiratory volume in $1 \mathrm{~s}$; FeNO: exhaled nitic oxide fraction; FVC: forced vital capacity; \% pred: \% predicted; FEF25-75\%: forced expiratory flow at 25-75\% of FVC; TLC: total lung capacity; FRC: functional residual capacity; RV: residual volume. ${ }^{*}$ : expressed as $100 \times$ (value after bronchodilation minus before (baseline))/before bronchodilation (baseline).

observed that most of the relationships found between BMI and clinical or functional characteristics disappeared when the z-score (both the BMI z-score and the forced expiratory flow z-score) and multiplicity of statistical tests were taken into account. Only FVC increased with the BMI z-score. The increase in FVC along with an increase in weight was further confirmed by a decrease in residual volume. We further observed that the relationship between the BMI z-score and both FEV1 and FVC was only related to female sex (table 4).

\section{Relationships with IOTF grade}

Differences in lung volume between the three IOTF grades were shown, whereas indices of airflow limitation and symptom-free days were similar (fig. 1). Similar levels of forced expiratory flow at $25-75 \%$ of FVC (FEF25-75\%) were observed in the three groups with no effect of sex (data not shown). There was no other difference in the clinical characteristics between the three groups (data not shown).

\section{DISCUSSION}

In our cross-sectional study using a prospective recruitment and two different methods to assess the changes associated with BMI, we first established that the BMI z-score (quantitative approach) was only related to mild spirometric changes (increased FVC and decreased residual volume (RV)), whilst symptoms were not altered by being overweight. First, we showed that overweight children, compared with normal weight children (qualitative analyses, using IOTF), were characterised by a decrease in static 


\begin{tabular}{|c|c|c|c|}
\hline \multirow[t]{2}{*}{ TABLE 3} & \multicolumn{3}{|c|}{$\begin{array}{l}\text { Relationships between body mass index (BMI) } \\
\text { and BMI z-score, and clinical or functional } \\
\text { characteristics }\end{array}$} \\
\hline & & $\begin{array}{c}\mathrm{BMI}^{*} \mathrm{p} \text {-value } \\
\text { (rho) }\end{array}$ & $\begin{array}{c}\text { BMI z-score } \\
\text { p-value (r-value) }\end{array}$ \\
\hline \multicolumn{2}{|c|}{ Females versus males } & 0.013 & 0.81 \\
\hline \multicolumn{2}{|l|}{ Age } & $<0.0001$ & $0.038(0.09)$ \\
\hline \multicolumn{4}{|l|}{ History } \\
\hline \multicolumn{2}{|l|}{ Birthweight } & $0.018(0.13)$ & $0.011(0.14)$ \\
\hline \multicolumn{2}{|c|}{ Early wheezing } & 0.36 & 0.028 \\
\hline \multicolumn{2}{|c|}{ Atopic dermatitis } & 0.52 & 0.31 \\
\hline \multicolumn{2}{|c|}{ Parental smoking } & 0.56 & 0.17 \\
\hline \multicolumn{4}{|l|}{ Atopic status } \\
\hline \multicolumn{2}{|c|}{ Negative/positive SPT } & 0.19 & 0.42 \\
\hline \multicolumn{4}{|l|}{ Treatment } \\
\hline \multicolumn{2}{|c|}{$\beta$-agonist on demand } & 0.22 & 0.93 \\
\hline \multicolumn{2}{|c|}{ ICS dose in treated children } & 0.60 & 0.30 \\
\hline \multicolumn{2}{|l|}{ LABA } & 0.85 & 0.84 \\
\hline \multicolumn{4}{|l|}{ Symptoms } \\
\hline \multicolumn{2}{|c|}{$\begin{array}{l}\text { Percentage of symptom- } \\
\text { free days }\end{array}$} & $0.043(0.09)$ & 0.84 \\
\hline \multicolumn{2}{|c|}{ Severe exacerbation } & 0.90 & 0.34 \\
\hline \multicolumn{2}{|c|}{ Exercise complaints (3 levels) } & 0.0001 & 0.024 \\
\hline \multicolumn{2}{|c|}{ Play team versus no symptom } & 0.75 & 0.77 \\
\hline \multicolumn{2}{|c|}{$\begin{array}{l}\text { Long-distance race versus } \\
\text { no symptom }\end{array}$} & $<0.0001$ & 0.006 \\
\hline \multicolumn{2}{|c|}{ Long-distance race versus play team } & 0.007 & 0.17 \\
\hline \multicolumn{4}{|c|}{ Baseline spirometry } \\
\hline \multicolumn{2}{|c|}{ FVC \% pred } & $<0.0001(0.19)$ & \\
\hline \multicolumn{2}{|c|}{ FVC z-score } & & $<0.0001(0.20)$ \\
\hline \multicolumn{2}{|c|}{ FEV $1 \%$ pred } & 0.27 & \\
\hline FEV 1 z-sco & & & $0.014(0.12)$ \\
\hline $\mathrm{FEV}_{1} / \mathrm{FVC}$ & & $0.0001(-0.19)$ & \\
\hline $\mathrm{FEV}_{1} / \mathrm{FVC}$ & pred & $0.01(-0.12)$ & \\
\hline $\mathrm{FEV}_{1} / \mathrm{FVC}$ & score & & $0.019(-0.11)$ \\
\hline FEF $25-75 \%$ & pred & 0.36 & \\
\hline FEF25-75\% & score & & 0.78 \\
\hline Baseline ple & nysmography & & \\
\hline $\mathrm{sRaw} \mathrm{kPa} \cdot \mathrm{s}$ & & $0.054(-0.09)$ & 0.57 \\
\hline TLC \% pre & & 0.42 & 0.24 \\
\hline FRC \% pre & & $0.0001(-0.17)$ & $0.001(-0.15)$ \\
\hline $\mathrm{FRC} / \mathrm{TLC}$ & & $0.002(-0.15)$ & $<0.0001(-0.24)$ \\
\hline RV \% pred & & $<0.0001(-0.23)$ & $0.002(-0.15)$ \\
\hline $\mathrm{RV} / \mathrm{TLC}$ & & $<0.0001(-0.38)$ & $<0.0001(-0.23)$ \\
\hline $\mathrm{BD}$ respon & FEV 1 & 0.93 & 0.83 \\
\hline BD respon & sRaw & 0.82 & 0.65 \\
\hline FeNO & & 0.99 & 0.16 \\
\hline
\end{tabular}

SPT: skin-prick test; ICS: inhaled corticosteroid; LABA: long-acting $\beta$-agonist; FVC: forced vital capacity; \%: pred: \% predicted; FEV1: forced expiratory volume in $1 \mathrm{~s}$; FEF25-75\%: forced expiratory flow at $25-75 \%$ of FVC; sRaw: specific airway resistance; TLC: total lung capacity; FRC: functional residual capacity; RV: residual volume; BD: bronchodilator; FeNO: exhaled nitric oxide fraction. \#: calculated according to Spearman; ': calculated according to Pearson. The results of the relationships between FEV1, FVC, FEF25-75\%, FEV1/FVC expressed as percentage predicted and BMI raw values (first column) are given for information and comparison with previous studies. $p$-values in bold remained significant after correction for multiple testing ( $p$-values are not modified; this is the level of significance that is set at a lower $p$-value).

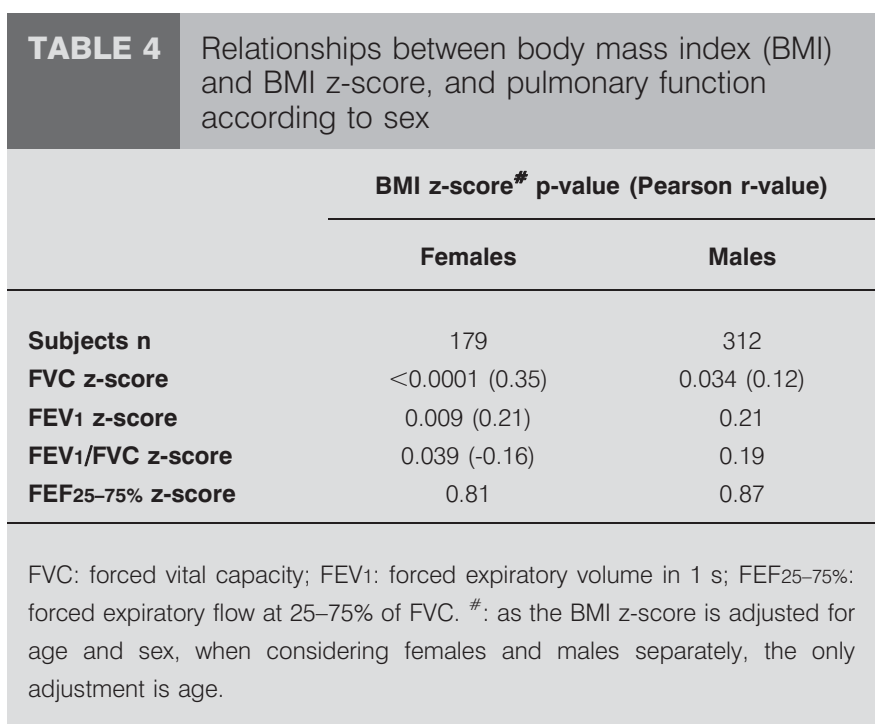

lung volumes (FRC and RV). Additionally, our study emphasises the need to express BMI as a z-score rather than as a raw value in order to take into account natural transitions in BMI during childhood and adolescence.

Obesity is an increasing health problem in children, but its relationship with asthma remains unclear. Paediatric studies mostly include mildly and/or recently overweight children, whereas adult studies include patients with a long obesity duration and severe obesity. Indeed, the effect of obesity on lung function was recently shown to be related to its duration in a population of 188 (aged 8-76 yrs) patients with or without asthma [24]. From a functional point of view, in adult patients, obesity is responsible for a reduction in lung volume associated with a reduction in the peripheral airway diameter. Over time, this phenomenon may disturb smooth muscle function, and potentially increase both airway obstruction and airway hyperreactivity [25]. As a consequence, obesity could be associated with a specific asthma phenotype (specific pathophysiology) [26] and/or with a worsening of asthma (worse control) [27], although these findings are under debate [28]. However, in line with these findings, young children with decreased physical activity, which favours the overweight condition, showed increased airway responsiveness [29], and children with a persistently high BMI during childhood or a high BMI at age 6-7 yrs were significantly at risk of dyspnoea and of airway hyperreactivity at age 8 yrs [30]. Unfortunately, we have no data on child fitness or physical activity in our study. Despite these results, the consequences of either being overweight or obesity on asthma might be more difficult to demonstrate in children than in adults, but searching for mild trends in childhood that may have long-term consequences in adulthood is crucial.

The clinical impact of overweight/obesity on asthma was found to be very mild in the CAMP study [8]. Only dyspnoea after a long-distance race was associated with increased BMI z-scores in our study, a result that became nonsignificant when the multiplicity of the statistical tests was taken into account. The comparison of children grouped according to the IOTF classification further confirmed the absence of a clinical difference. We found no association between BMI and the occurrence of 

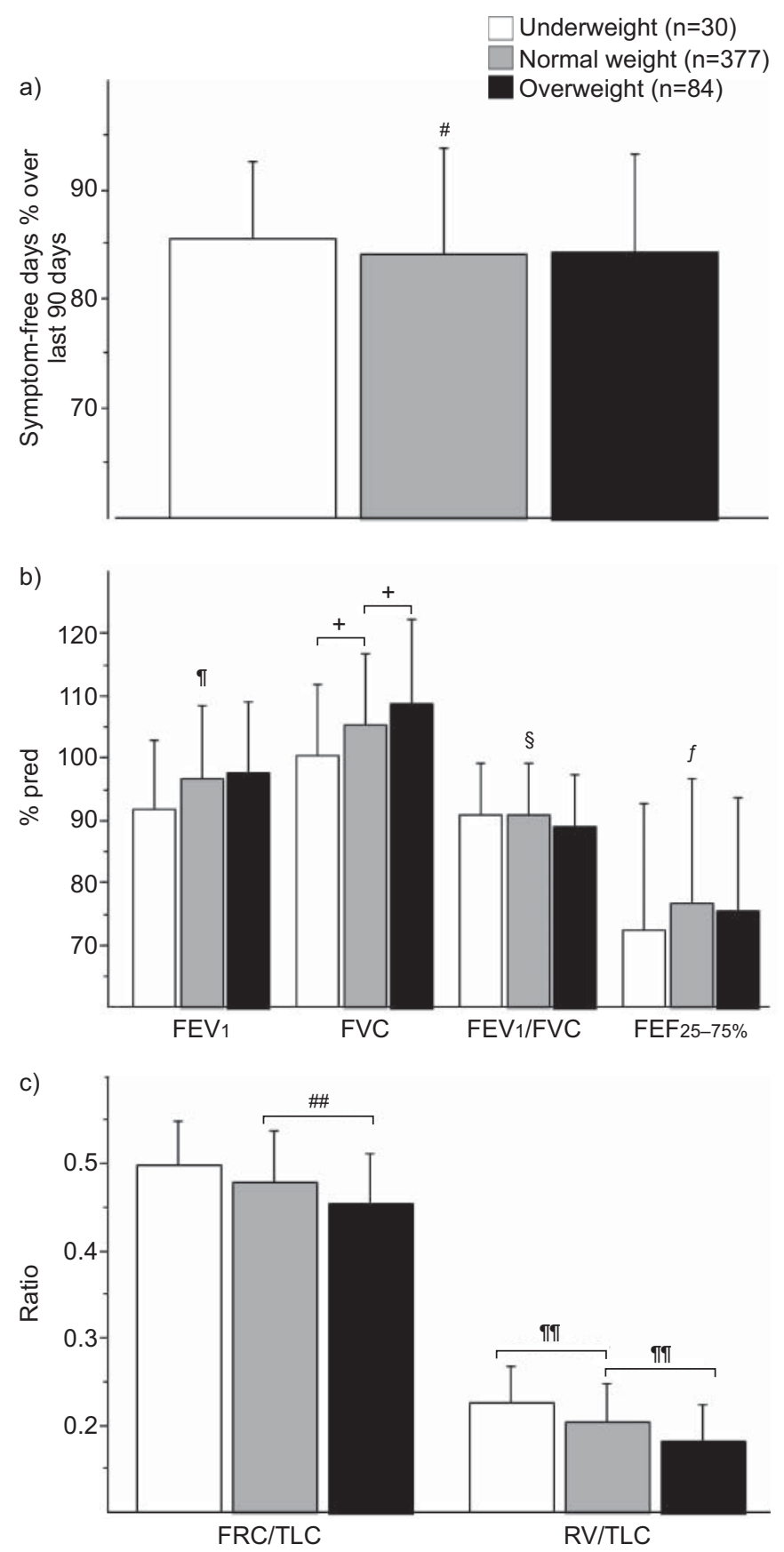

FIGURE 1. a) Clinical and b, c) functional indices for subjects according to three grades based on International Obesity Task Force classification. \% pred: \% predicted; FEV1: forced expiratory volume in $1 \mathrm{~s}$; FVC: forced vital capacity; FEF2575\%: forced expiratory flow at $25-75 \%$ of FVC; FRC: functional residual capacity; TLC: total lung capacity; RV: residual volume. ${ }^{\#}: p=0.75 ;{ }^{\top}: p=0.08 ;^{+}: p=0.005$; s: $p=0.29 ;{ }^{f}: p=0.50{ }^{\# \#: ~} p=0.001 ;{ }^{\text {थศ: }} p<0.0001$.

exacerbations; we also found no evidence that atopy was influenced by BMI, as previously reported [8, 12]. The burden of asthma treatment and the number of symptom-free days were not related to BMI, in contrast to the results of previous studies [6, 31]. However, it is difficult to compare these results, partly because the outcomes of the different studies were differently assessed [6, 31]. Moreover, we used a standard lung function criterion (i.e. previously demonstrated reversibility), whereas many previous studies were based on self-reported or doctordiagnosed asthma or on the use of asthma medication. This might be misleading as overweight/obese children have more respiratory symptoms, particularly upon physical exertion, but inconsistent objective criteria for asthma, as recently highlighted [32, 33]. When more stringent criteria were used to define asthma, no relationship between BMI and asthma severity was evidenced in asthmatic children and adults [34].

Overall, when considering raw BMI values in our study, our results on lung function closely matched those obtained in the CAMP study [8]. There was a positive relationship between BMI and FEV1, and a decrease in FEV1/FVC (raw value) with increasing BMI. In calculating the reference values for FEV1 and FVC, early studies concluded that an adjustment for weight was unnecessary because the additional explained variance was small after adjustments for height, sex and ethnicity [35]. However, the raw BMI value encompasses a growth dimension and morphological changes with growth that should not be interpreted as bodyweight effects. When taking into account these potential biases, there was still a statistically significant relationship between the BMI z-score and the FVC z-score, but the explained variance was low $(4 \%)$, which is consistent with the previous statements. BMI and waist circumference are more indicative of body size than of fat mass and, therefore, are usually positively associated with pulmonary function [36]. However, in the study of CHEN et al. [36], after adjustments for sex, age and height, waist circumference remained positively associated with FVC and FEV1 but negatively associated with FEV1/FVC. The apparent discrepancy between changes in forced volumes and their ratio, as previously mentioned for obese children, could be attributed to the variable effect of weight according to the level of (over)weight, as demonstrated by SCHOENBERG et al. [37] in 3,046 healthy subjects (aged $>7$ yrs). Lung function increased with a moderate weight increase, then decreased with a further increase in weight. This result was later supported and explained by a study conducted on 2,464 school children for whom heightadjusted FVC and FEV1 values increased significantly with increasing weight, and decreased significantly with increasing total body fat [38]. Our study, which included overweight but few obese children, could not demonstrate this two-step relationship with weight on lung function.

Accordingly with the results of the CAMP study, the increase in FVC was related to BMI only in females. This sex effect could be highlighted because of the earlier growth spurt in females as compared with males and age inclusion criterion (children between 6 and 15 yrs of age), and, more importantly, this sex effect is probably related to the earlier onset of puberty in overweight females [39]. The higher degree of statistical significance between BMI z-score and FVC than with FEV1 (which incorporates both volume and calibre components) could further be related to dysanaptic lung growth in females [40], explaining the trend for statistical significance for the decrease in FEV1/FVC. This latter decrease is not related to airway remodelling. The absence of a true airflow limitation was further confirmed by the similar levels of FEF25-75\% predicted in overweight and normal children (fig. 1). This latter result is consistent with the results displayed by both our group and the CAMP study, showing that a "decline in lung function" is a rare event in asthmatic children $(\sim 25 \%)$ that mainly affects males $[41,42]$. 
We confirmed the association between being overweight and modifications of lung volumes (RV/total lung capacity (TLC) and FRC/TLC) using two approaches: namely the BMI z-scores and IOTF grades. We did not observe a reduction in TLC (restrictive defect), which is a rare pattern, even in adults $[43,44]$. This could have been related to the low prevalence of severe obesity in our series. The reduction in the RV/TLC ratio could be related to growth only [45], whilst the reduction in the FRC/TLC ratio characterised overweight children but had trivial significance. It has long been known that for the description of FRC, the inclusion of a term for percentage body fat reduces the variance about the regression equation of reference values for indices of lung function [46].

Our study suffers from the limitations common to cross-sectional studies. Certainly, the association between BMI and pulmonary function cannot demonstrate causality or even the direction of the relationship. Our explanations (earlier puberty and dysanaptic lung growth) for the observed relationships remain speculative, but are supported by available literature [39, 40]. It would be interesting to further assess these relationships according to pubertal status in females being overweight, as previously performed in healthy populations $[47,48]$. We have to acknowledge that some non-Caucasian children (mainly from the French Antilles) were enrolled, despite the sole use of STANOJEVIC et al. [13] reference values. However, our monocentre study conducted in a Paris suburb addressed a population that was representative of the French population, as the prevalence of overweight $[49,50]$ and the severe exacerbation rate [51] were as expected. Finally, the absence of consequences of being overweight on asthma control may be related to the short duration of being overweight in our population, and to the lack of obese children. We used a correction for multiple comparisons because, when a large number of statistical tests are performed, the risk of false-positive findings increases considerably. In order to control the expected proportion of errors among the rejected hypotheses, the false discovery rate was used, which is still debated when conducting a hypotheses generator physiological study.

In conclusion, our cross-sectional study shows slight relationships between functional indices (increased FVC and FEV1 in females) and being overweight, while characteristics of asthma (symptoms, level of treatment and airflow limitation) were not altered by being overweight. Analyses using IOTF classification further showed that, compared with normal weight children, overweight children are characterised by a decrease in some static lung volumes without clinical consequences.

\section{STATEMENT OF INTEREST}

None declared.

\section{ACKNOWLEDGEMENTS}

The authors wish to thank P. Tounian (Dept of Pediatric Nutrition, Armand Trousseau Hospital, Paris, France) for advice concerning the manuscript and L. Trinquart (member of the Mosquito Research Group; INSERM U738, Paris, France) for statistical advice.

\section{REFERENCES}

1 Camargo CA Jr, Weiss ST, Zhang S, et al. Prospective study of body mass index, weight change, and risk of adult-onset asthma in women. Arch Intern Med 1999; 159: 2582-2588.
2 Figueroa-Munoz JI, Chinn S, Rona RJ. Association between obesity and asthma in 4-11 year old children in the UK. Thorax 2001; 56: 133-137.

3 de Groot EP, Duiverman EJ, Brand PL. Comorbidities of asthma during childhood. possibly important, yet poorly studied. Eur Respir J 2010; 36: 671-678.

4 Carroll CL, Bhandari A, Zucker AR, et al. Childhood obesity increases duration of therapy during severe asthma exacerbations. Pediatr Crit Care Med 2006; 7: 527-531.

5 Carroll CL, Stoltz P, Raykov N, et al. Childhood overweight increases hospital admission rates for asthma. Pediatrics 2007; 120: 734-740.

6 Vargas PA, Perry TT, Robles E, et al. Relationship of body mass index with asthma indicators in head start children. Ann Allergy Asthma Immunol 2007; 99: 22-28.

7 Kwong KY, Rhandhawa I, Saxena J, et al. Ability to control persistent asthma in obese versus non-obese children enrolled in an asthma-specific disease management program (breathmobile). J Asthma 2006; 43: 661-666.

8 Tantisira KG, Litonjua AA, Weiss ST, et al. Association of body mass with pulmonary function in the Childhood Asthma Management Program (CAMP). Thorax 2003; 58: 1036-1041.

9 Kattan M, Kumar R, Bloomberg GR, et al. Asthma control, adiposity, and adipokines among inner-city adolescents. J Allergy Clin Immunol 2010; 125: 584-592.

10 Cole TJ, Bellizzi MC, Flegal KM, et al. Establishing a standard definition for child overweight and obesity worldwide: international survey. BMJ 2000; 320: 1240-1243.

11 Cole TJ, Freeman JV, Preece MA. Body mass index reference curves for the UK, 1990. Arch Dis Child 1995; 73: 25-29.

12 He QQ, Wong TW, Du L, et al. Respiratory health in overweight and obese Chinese children. Pediatr Pulmonol 2009; 44: 997-1002.

13 Stanojevic S, Wade A, Cole TJ, et al. Spirometry centile charts for young Caucasian children: the Asthma UK Collaborative Initiative. Am J Respir Crit Care Med 2009; 180: 547-552.

14 The Global Initiative for Asthma (GINA). Global Strategy for Asthma Management and Prevention, 2007. www.ginasthma.com Date last accessed October 15, 2009.

15 Mahut B, Peiffer C, Bokov P, et al. Use of specific airway resistance to assess bronchodilator response in children. Respirology 2011; 16 : 666-671.

16 Reddel HK, Taylor DR, Bateman ED, et al. An official American Thoracic Society/European Respiratory Society statement: asthma control and exacerbations: standardizing endpoints for clinical asthma trials and clinical practice. Am J Respir Crit Care Med 2009; 180: 59-99.

17 Mahut B, Peiffer C, Thibaudon M, et al. What does a single exhaled nitric oxide measurement tell us in asthmatic children? J Asthma 2009; 46: 810-814.

18 Mahut B, Bokov P, Delclaux C. Abnormalities of plethysmographic lung volumes in asthmatic children. Respir Med 2010; 104 : 966-971.

19 Mahut B, Trinquart L, Bokov P, et al. Relationships between specific airway resistance and forced expiratory flows in asthmatic children. PLoS One 2009; 4: e5270.

20 Stocks J, Quanjer PH. Reference values for residual volume, functional residual capacity and total lung capacity. ATS Workshop on Lung Volume Measurements. Official Statement of the European Respiratory Society. Eur Respir J 1995; 8: 492-506.

21 Benjamini $Y$, Yekutieli D. The control of the false discovery rate in multiple testing under dependency. Ann Stat 2001; 29: 1165-1188.

22 Hsieh FY, Bloch DA, Larsen MD. A simple method of sample size calculation for linear and logistic regression. Statist Med 1998; 17: 1623-1634.

23 Quanjer PH, Borsboom GJ, Kivastik J, et al. Cross-sectional and longitudinal spirometry in children and adolescents: interpretative strategies. Am J Respir Crit Care Med 2008; 178: 1262-1270. 
24 Santamaria F, Montella S, Greco L, et al. Obesity duration is associated to pulmonary function impairment in obese subjects. Obesity (Silver Spring) 2011; 19: 1623-1628.

25 Beuther DA, Weiss ST, Sutherland ER. Obesity and asthma. Am J Respir Crit Care Med 2006; 174: 112-119.

26 Haldar P, Pavord ID, Shaw DE, et al. Cluster analysis and clinical asthma phenotypes. Am J Respir Crit Care Med 2008; 178: 218-224.

27 Simard B, Turcotte H, Marceau P, et al. Asthma and sleep apnea in patients with morbid obesity: outcome after bariatric surgery. Obes Surg 2004; 14: 1381-1388.

28 Sutherland ER, Lehman EB, Teodorescu M, et al. Body mass index and phenotype in subjects with mild-to-moderate persistent asthma. J Allergy Clin Immunol 2009; 123: 1328-1334.

29 Brasholt M, Baty F, Bisgaard H. Physical activity in young children is reduced with increasing bronchial responsiveness. J Allergy Clin Immunol 2011; 125: 1007-1012.

30 Scholtens S, Wijga AH, Seidell JC, et al. Overweight and changes in weight status during childhood in relation to asthma symptoms at 8 years of age. J Allergy Clin Immunol 2009; 123: 1312-1318.

31 Luder E, Melnik TA, DiMaio M. Association of being overweight with greater asthma symptoms in inner city black and Hispanic children. J Pediatr 1998; 132: 699-703.

32 Matricardi PM, Gruber C, Wahn U, et al. The asthma-obesity link in childhood: open questions, complex evidence, a few answers only. Clin Exp Allergy 2007; 37: 476-484.

33 Peroni DG, Pietrobelli A, Boner AL. Asthma and obesity in childhood: on the road ahead. Int J Obes (Lond) 2010; 34: 599-605.

34 Peters JI, McKinney JM, Smith B, et al. Impact of obesity in asthma: evidence from a large prospective disease management study. Ann Allergy Asthma Immunol 2011; 106: 30-35.

35 Dockery DW, Berkey CS, Ware JH, et al. Distribution of vital capacity and forced expiratory volume in one second in children 6 to 11 years of age. Am Rev Respir Dis 1983; 128: 405-412.

36 Chen Y, Rennie D, Cormier Y, et al. Waist circumference associated with pulmonary function in children. Pediatr Pulmonol 2009; 44: 216-221.

37 Schoenberg JB, Beck GJ, Bouhuys A. Growth and decay of pulmonary function in healthy blacks and whites. Respir Physiol 1978; 33: 367-393.

38 Lazarus R, Colditz G, Berkey CS, et al. Effects of body fat on ventilatory function in children and adolescents: cross-sectional findings from a random population sample of school children. Pediatr Pulmonol 1997; 24: 187-194.

39 Kaplowitz PB, Slora EJ, Wasserman RC, et al. Earlier onset of puberty in girls: relation to increased body mass index and race. Pediatrics 2001; 108: 347-353.

40 Merkus PJ, Borsboom GJ, Van Pelt W, et al. Growth of airways and air spaces in teenagers is related to sex but not to symptoms. J Appl Physiol 1993; 75: 2045-2053.

41 Covar RA, Spahn JD, Murphy JR, et al. Progression of asthma measured by lung function in the childhood asthma management program. Am J Respir Crit Care Med 2004; 170: 234-241.

42 Mahut B, Trinquart L, Bokov $\mathrm{P}$, et al. Lung function impairment evidenced by sequential specific airway resistance in childhood persistent asthma: a longitudinal study. J Asthma 2010; 47: 655-659.

43 Collet F, Mallart A, Bervar JF, et al. Physiologic correlates of dyspnea in patients with morbid obesity. Int J Obes (Lond) 2007; 31: 700-706.

44 Inselma LS, Milanese A, Deurloo A. Effect of obesity on pulmonary function in children. Pediatr Pulmonol 1993; 16: 130-137.

45 Quanjer PH, Stanojevic S, Stocks J, et al. Changes in the FEV/FVC ratio during childhood and adolescence: an intercontinental study. Eur Respir J 2010; 36: 1391-1399.

46 Cotes JE, Dabbs JM, Hall AM, et al. Sitting height, fat-free mass and body fat as reference variables for lung function in healthy British children: comparison with stature. Ann Hum Biol 1979; 6: 307-314.

47 Neve V, Girard F, Flahault A, et al. Lung and thorax development during adolescence: relationship with pubertal status. Eur Respir J 2002; 20: 1292-1298.

48 Trabelsi Y, Tabka Z, Richalet JP, et al. Spirometric values in Tunisian children: relationship with pubertal status. Ann Hum Biol 2007; 34: 195-205.

49 Deschildre A, Pin I, Gueorguieva I, et al. Asthme et obésité : quelle relation chez l'enfant? [Asthma and obesity in childhood: what is the link?]. Arch Pediatr 2009; 16: 1166-1174.

50 Jebb SA, Rennie KL, Cole TJ. Prevalence of overweight and obesity among young people in Great Britain. Public Health Nutr 2004; 7: 461-465.

51 Mahut B, Trinquart L, Delclaux C. Influence of age on the risk of severe exacerbation and asthma control in childhood. J Asthma 2011; 48: 65-68. 